\title{
التفاوت الشعري عند الثاعر وموقف نقاد القرن الثالث الهجري منه
}

\section{محمود محمد ملودة

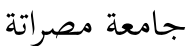

\author{
عبدالسلام مخزوم الشيماوي \\ الجامعة الأسمرية الإسلامية
}

تاريخ التقديم: 07-10-2019 ، تاريخ القبول: 29-10- 2019، نشر إلكترونيا في 30-10-2019 https://doi.org/10.36602/faj.2019.n14.05

ملخص البحث:

التفاوت الشعري لم يرد بوصفه مصطلحا نقديا في معاجم النقد ولا في كتب

الأدب والبلاغة، ولكنه كان حاضرا في مستويي: الإنتاج والتلقي، بمعناه ودلالته في الممارسة النقدية عند نقاد القرن الثالث الهجري، واختيار هذا الزمن كان مقصودا، إذ عرف النقد في هذا القرن التفلت من الدائرة الذاتية، والانفتاح على المرجعيات اللغوية وعلم الكلام والفلسفة. وينهض البحث على تجميع المصطلحات النقدية التي تدخل ضمن دائرة التفاوت، ويحاول دراستها عبر مصفوفتين معرفيتين، الأولى تبحث في المصطلح والمفهوم، والأخرى ترصد الظاهرة في الإنتاج الشعري والتلقي النقدي. وسنتعرف على التفاوت الشعري في علاقته بمصطلحات قريبة كالتناقض والتباين والاختلاف، ثم نرصد أسباب

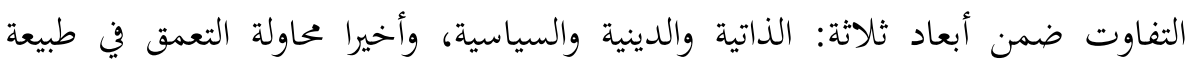
التفاوت الشعري وفهم عمله، وقد أفضى التقصي إلى ثلاثة خطوط يتحرك وفقها التفاوت، وهي: ما يتصل بالموضوع الشعري أولا ، ثم ما تقتضيه عمليات التلقي ثانيا، وثالثا ما يرتن إلى الشاعر نفسه، وكان من نتاج ذلك سهولة تسكين ذلك في خطاطة

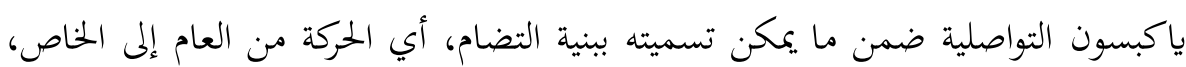
حيث تبدأ عملية التفاوت من السياق (الموضوع الشعري) ثم المرسل إليه (الرواة) وانتهاء

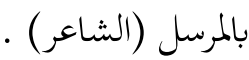

الكلمات المفتاحية: الشعر العربي - النقل في القرن الثالث الهجري - الثغاوت الشعري m.emluda67@gmail.com ${ }^{1}$ 


\title{
Poetic Disparity of Poets and the Attitudes of Critics in the Third Century A.H
}

Abdulsalam Alshimmawi

Al-asmarya Islamic University
Mahmud Mlouda

Misurata University

\begin{abstract}
'Disparity' did not appear as a literary term in the glossaries of criticism nor it did in rhetoric and literature books. However, it was present on two levels: the production and the reception, in its meaning in critical practice of the Critics of the Third Century A H. The paper is meant to gather critical terms that fall within the ' Disparity' circle, and tries to study them through two cognitive matrices. The first looks at the term and concept, and the second monitors the phenomenon in poetic production and reception.
\end{abstract}

We will identify poetic Disparity in relation to nearer terms such as contradiction, discrepancy and difference. Then, we will examine the causes of Disparity within three dimensions: the subjective, religious and political, and finally try to delve deeper into the nature of poetic disparity and understand how it works.

The investigation has led to three lines according to which the Disparity occurs. The first is related to the theme of the poetry itself, the second is what the processes of reception require, and the third depends on the poet himself. As result, it became easier to locate it in f Jacobson communicative plan within what can be called the structure of connectedness, i.e. the movement from general to specific, where the process of Disparity starts from the context (poetic theme), the narrators and ending with the sender (poet).

key words: Arabic poetry - criticism in the third century AH - poetic disparity 
يكشف اهتمام النقاد بظاهرة التفاوت الشعري عن وعي نقدي مبكر، أثارته معطيات فكرية وثقافية وحضارية، لعل أهمها تلك النقلة الحضارية، التي تحققت للعلوم العربية في عصر التدوين، بانتقالها من عصر الشفاهية إلى عصر الكتابية، التي هيأت المناخ النقدي للاتساع والتطور، بفعل حفظ التجارب النقدية وتراكمها وانتشارها، وسمحت يمراجعة الكثير من الأفكار النقدية السائدة، ومنها التوقف عند مصدر الظاهرة الشعرية، وانحسار الفكرة السائدة، التي كانت تُرجع الإبداع الشعري إلى قوى خارجية، من اعتقادات

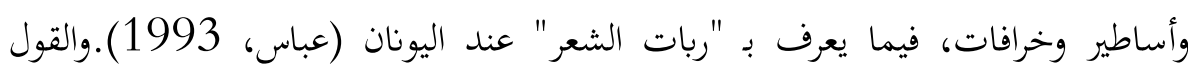

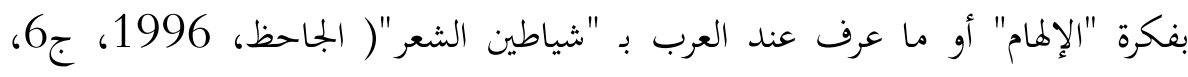
ص.226)، وردها إلى قوى داخلية، أي إلى عالم إنساني يصدر عن الشاعر.

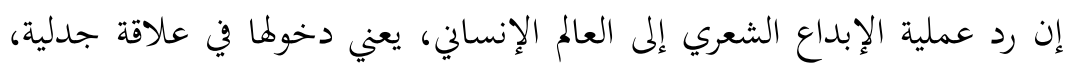
وصراع مستمر مع الشاعر، إذ تُسْلم له قيادها تارة، وتتأبى الانقياد تارة أخرى، فيأتي شعره صورة من صور هذا الجدل والصراع، وبه يتحقق الاختلاف في شعره، وقد يمر الشاعر بمنعطفات كبرى في حياته، ويتبع ذلك اضطراب في نتاجه الشعري بالضرورة، إذ يفقد وحدة نسيجه، ونظام مساراته، فيوسم شعره بالتفاوت والتناقض.

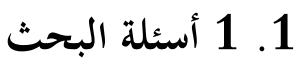
يطرح البحث بمناهج بحثية حديثة أسئلة على تراثنا النقدي: ما معنى التفاوت الشعري؟ ولماذا عني نقاد القرن الثالث الهجري به؟ ما أسباب التفاوت؟ وكيف قرأ النقاد بنهاد هذه الظاهرة الشعرية في الديوان الشعري العرب؟ كيف نستفيد من التفاوت مصطلحا ومفهوما في نقدنا المعاصر؟ 


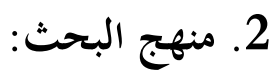

تم الاستعانة في المرحلة الأولى بالمنهج الوصفي التحليلي، حيث ارتن الوصفي بالمعالجة النظرية وتقديم الإطار المعريف للمصطلح والمفهوم، بينما تولى التحليل دراسة المقولات النقدية قصد استخراج المفهوم منها، ويف المرحلة الثانية استأنس البحث بالمنهج الاستدلالي المقارن، حيث وضع كل نقاد القرن الثالث في دائرة الاستقراء واستصفاء المتشابه والمختلف في مقولاهم النقدية، ثم المقارنة بينهم قصد التوفر على النظام الكامل لعمل مصطلح التفاوت وخطواته الإجرائية.

3. المبحث الأول: التفاوت في دائرة المصطلح والمفهوم 3. 1 تحديد مصطلح التفاوت الثعري: 3. 1 . 1 التفاوت في اللغة:

تُطلق كلمة التفاوت وما هو من جذرها في اللغة على معان عدة، منها:

1. الاختلاف والتباين والاضطراب، تقول: تفاوت الشيئان: "اختلفا في التقدير، ويقال: تباين الرجالان تباينا في الفضل، وتفاوت الخَلْق: اختلف ولم يكن سويا" (بحمع اللغة العربية، 2005، ج2 ص.731)، ومن ذلك قوله تعالى: "الذي خلق سبع سموت طباقا ما ترى في خلق الرحمن من تفاوت فارجع البصر هل ترى من فطور" (سورة الملك، الآية 3)، والمعنى: ما ترى في خلقه تعالى السماء اختلافا، وقرى من تفوُّت: بمعنى من عيب، وقيل هما بمعنى واحد. وذهب الفخر الرازي إلى أن حقيقة التفاوت في الآية الكريمة هو: "عدم التناسب، كأن بعض الشيء يفوت بعضه ولا يلائمه" (الرازي، 2000، ج30، ص. 51)، وعلى هذا المعنى فإن نفي التفاوت لا يعني التطابق والتماثل، بل يعني نفي عدم 
الملاعمة أو نفي عدم التناسب، ويبدو هذا الفهم أكثر اتساقا مع الآيات الكريمة، التي تؤكد صراحة اختلاف البشر، أو عدم تطابقهم في خصائص كثيرة، كالألسنة والألوان وغيرها، كما في قوله تعالى: "ومن ءايته خلق السموت والأرض واختلاف ألسنتكم وألوانكم إن في ذلك sلايت للعلمين" ( سورة الروم، الآية 21)، ولعل الاختلاف هنا هو اختلاف في الدرجة لا في النوع، وهو ما يحقق التناسب دون التفاوت، خلافا لمن يرى: "أن نفي التفاوت يحقق معنى التطابق، أي التماثل" (بن عاشور، ب ت، ج29، ص.17) وأن أصل الكلام: ما ترى فيهن ولا في خلق الرحمن من تفاوت. 2. التباعد بين الشيئين، قال ابن منظور: "تفاوت الشيئان أي تباعد ما بينهما"(ابن منظور، 1990، ج2، ص.69) والتفاوت بوزن التفاعل: شدة الفوت، والفوت: البعد، والتفاعل هنا ليس على حقيقته، بل هو للمبالغة، وهو هنا مستعار للتخالف وانعدام التناسق، لأن عدم المناسبة يشبه البعد بين الشيئين، تشبيه معقول بمحسوس (بن عاشور،

$$
\text { ب ت، ج29، ص.29 }
$$

3. إحداث الشيء والانفراد به دون أمر صاحبه، قال ابن منظور: افتات عليه في الأمر: حكم، وكل من أحدث دونك شيئا فقد فاتك به، ومنه قول معن بن أوس يعاتب امرأته: فإن الصبح منتظرُ قريب

أي لا أفوتك، ولا يفوتك ملامي إذا أصبحت، فدعيني ونومي إلى أن نصبح. 4. السبق، ومضي الوقت على شيء لم يُفعل، قال ابن منظور: فاتني كذا أي سبقني، ... وفاتني الأمر فوتا وفواتا ذهب عني، ومنه قول أبي ذؤيب:

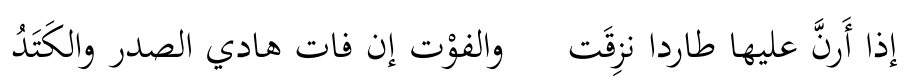


أي إن فاتته لم تفته إلا بقدر صدرها ومنكبها، ومن معانيه أيضا، الخلل، والفرجة بين الأصابع، والموت الفجأة (ابن منظور، 1990، ج2، ص.69) 3. 1. 2 1.

لم يرد مصطلح التفاوت في معاجم النقد الأدبي القديم ولا في معاجم البلاغة، ولكنه كان حاضرا بمعناه ودلالته في الممارسات النقدية، عند نقاد القرن الثالث الهجري، فكثير من الأحكام النقدية تتأسس على المعاني اللغوية لهذه الكلمة، كالاختلاف، والتباين، والاضطراب، والتباعد بين الشيئي، والسبق، فهذه القصيدة تأتي في صدارة شعر هذا الشاعر، وتلك تختلف في مستواها الفني عن بقية قصائده، وأخرى مضطربة قياسا ببقية شعره، وكثير من الشعراء عرفوا بقصيدة واحدة من قصائدهم واشتهروا بها، أو أبيات أو بيت محدد من بين أشعارهم، ومما يؤكد وعي النقاد بالتفاوت الشعري، أن النقد العربي القديم يعتمد في جل أحكامه النقدية على صيغة أفعل التفضيل، وهذه الصيغة تقوم في أساسها على المفاضلة، وهي أساس التفاوت الشعري. إن المنجز الشعري لأي شاعر لن يكون متطابقا بعضه مع بعض، بل لابد أن أن يكون مختلفا؛ لأنه في حال المطابقة هذه سيكون تكريرا، كما أن اختلافه لا يتعارض مع كونه يسير على نسق واحد، أو وتيرة واحدة، وعندما يحدث اختلال في هذا النسق أو تلك الوتيرة، يمكننا القول إن شعر هذا الشاعر متفاوت، ومن ثم فإن ربط التفاوت بمعنى الاختلاف وحده، لا يؤدي هذا المعنى، ففي التفاوت اختلاف وزيادة، وهي الاضطراب والتباعد بين الشيئين، وشدة الفوت، أي عدم التناسب وعدم التقارب من الناحية الفنية. وقد تنبه النقاد المعاصرون إلى هذه الظاهرة النقدية القديمة، فوسع بعضهم من دلالتها، عندما استخدم المصطلح في التفريق بين نوعين من الشعر الغنائي، هما: القصيد 
والرجز، ووصف العلاقة بينهما بالتفاوت في درجة الغنائية (إبراهيم، 1985، ص46)، واستخدمه البعض الآخر في نطاق لا يتجاوز شعر الشاعر، إذ حدد التفاوت الشعري بأنه: "هو التفاوت في القصيدة أو في شعر الشاعر الواحد" (عباس، 1993، ص 64 64) ويتفق البحث في استخدامه مصطلح التفاوت مع هذا المعنى. 3. 2 التناقض وعلاقته بمصطلح التفاوت: إن ربط التفاوت الشعري بنفي التناسب والتقارب، يجعله يتقاطع في بعض دلالاته مع مصطلح التناقض الشعري، تقول: ناقض فلان في كلامه تكلم بما يخالف معناه، وتناقض الكلامان: ادّافعا، كأن الواحد منهما ينقض الآخر بإبطاله (الناقوزي ، 1984،

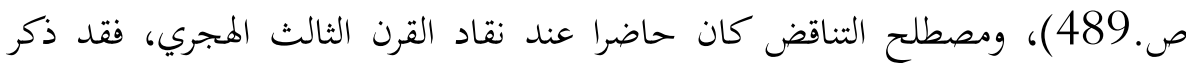
محمد بن سلام الجمحي "أن عبد الله بن رواحة، ... كان في حروبهم في الجاهلية يناقض

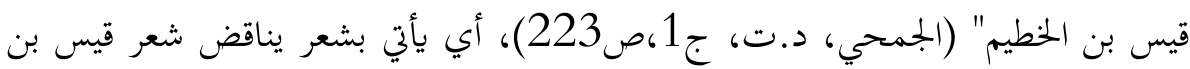

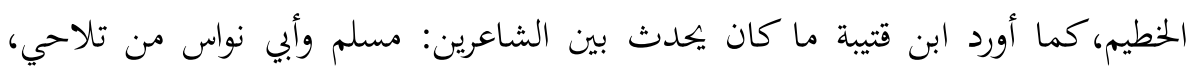
وفيها أن أبا نواس طلب من مسلم أن ينشده، فأنشده:

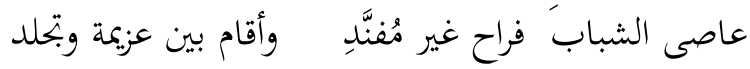

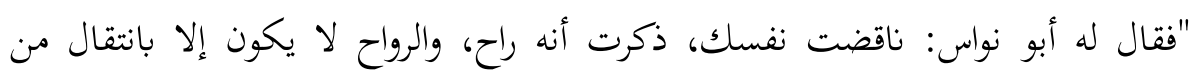
مكان إلى مكان، ثم قلت: وأقام بين عزيمة وبجلد، فجعلته منتقلا مقيما" (ابن قتيبة، 1958، ج2، ص 806) فالرواح بحسب أبي نواس يقتضي الانتقال، والانتقال يتناقض مع الإقامة، وهذ دليل على حضور مصطلح التناقض عند نقاد القرن الثالث الهجري.

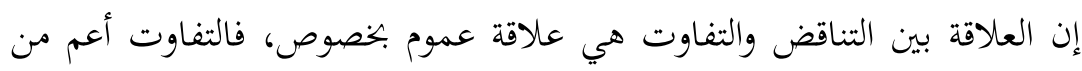

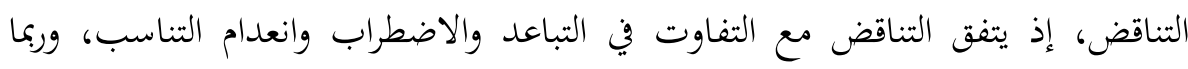


يتجاوز ذلك إلى الإفساد والهدم، وتدخل هذه المعاني في التفاوت الشعري، وهذا ما يلتقي فيه هذان المصطلحان، ولذلك يُستخدمان بمعنى واحد في هذا البحث، برغم ما بينهما من اختلاف.

3. 3 أنماط التفاوت الشعري:

هناك نمطان من التفاوت الشعري:

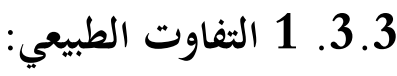

وهو الذي يحدثه التطور الناشئ عن تراكم الخبرة الشعرية عند الشاعر من ناحية، واختلاف الموضوع من ناحية ثانية؛ إذ إن دينامية الشعر مرتبطة ارتباطا وثيقا بحركة الحياة وتحولاتحا (إسماعيل، 2007، ص 12)، وهذا البحث ليس معنيا بهذا النوع من التفاوت؛ لأن هذا النوع لا يستوعب كل معاني التفاوت، فهو أقرب إلى الاختلاف منه إلى التفاوت، وهو تفاوت طبيعي، يحدث في المنجز الشعري للشعراء جميعهم، مثلما يحدث في مناحي الحياة كلها، بل هو معني بنمطه الثاني، وهو ما يمكن تسميته بالتفاوت الظاهر. 3. 3. 3.

وهو ما نحاول مقاربته في هذا البحث، ونعني بالتفاوت الظاهر: التباين الواضح،

الذي يحدث في المنجز الشعري للشاعر، بسبب اختلاله أو فقدان تناسبه واتساقه من الناحية الفنية، مع أقواله الشعرية السابقة عليه أو اللاحقة، وقد حفظت المصادر العلمية القديمة، بعض الأحكام النقدية، المؤسسة على التفاوت الشعري عند الشاعر، ويمكن الوقوف على ذلك في تعقبات العلماء والنقاد للشعراء، وقد جمع المرزباني في كتابه: الموشح، "مآخذ العلماء على الشعراء في عدة أنواع من صناعة الشعر" كثيرا من هذه التعقبات، والكتاب دال بعنوانه وموضوعه. 
إن المتتبع لموقف النقد العربي القديم من هذه الظاهرة الشعرية، سوف يجد الكثير من الأحكام النقدية التي تلقى فيها التهم على الشعراء، بسبب تفاوت أشعارهم وتناقضاقا، ونكتفي بضرب مثال واحد يؤدي هذا المعنى: من ذلك ما عابوه من تناقض امرئ القيس في قوله: فتوضِح فالمقراة لم يعف رسمها

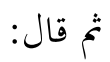
وهل عند رسم دارس من معوّل؟ - (- من

$$
\text { وعلى زهير بن أبي سُلمى في قوله: }
$$

قف بالديار التي لمم يعفها القدم

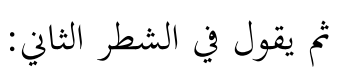

$$
\text { بلى وغيرّها الأرواح والديم }
$$

حيث ذكرت الرواة أن الشاعر أكذب نفسه (المرزباني، د.ت، ص33).

ويذكر أبوبكر الأنباري الاختلاف الذي دار بين العلماء في تأويل ظاهرة التناقض الشعري في البيتين السابقين فيقول: "إن قال قائل: كيف قال في البيت الأول: (لم يعف رسمها) فخبر أن الرسم لم يدرس، وقال في هذا البيت: (عند رسم دارس)؟ قيل له: في هذا غير قول: قال الأصمعي: قد درس بعضه وبقي بعضه ولم يذهب إلى كله، كما تقول: قد درس كتابك، أي ذهب بعضه وبقي بعضه. وقال أبو عبيدة: رجع فأكذب نفسه بقوله: (فهل عند رسم دارس) كما قال زهير:

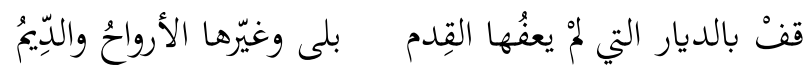


وقال آخرون: ليس قوله في هذا البيت: (فهل عند رسم دارس) بناقض لقوله: (لم يعف رسمها) لأن معناه لم يدرس رسمها من قلبي، وهو نفسه دارس. وقالوا أراد زهير في بيته: قف لف بالديار التي لم يعفها القدم من قلبي، ثم رجع إلى معنى الدروس فقال: (بلى وغيّها الأرواح والديم).

وقال آخرون: معنى (فهل عند رسم دارس) الاستقبال، كأنه قال: فهل عند رسم سيدرس بمرور الدهر عليه، وهو الساعةَ باق. كما تقول: زيد قائم غدا، معناه: زيد يقوم غدا" (ابن الأنباري، د.ت، ص26)، ويتضح من خلال هذه الآراء أن أغلبها لا يسلّم بالعيب الذي لاحظه النقاد السابقون على البيتين، بسبب التناقض فيهما، ومن ثم ينتفي العيب عنهما، ويلجأ أصحابها إما إلى التأويل (الرأي الثالث) أو إلى ما تسمح به الدلالات اللغوية (الأصمعي وأصحاب الرأي الرابع) وهذا ينم عن فهم جيد لطبيعة النص الشعري، ولم يشذ عن ذلك إلا أبو عبيدة.

وفي مراحل متأخرة (القرن الرابع الهجري) لم يتسامح النقاد في مسألة التناقض الشعري عند الشاعر فحسب، بل يعدوها دليلا على القدرة الشعرية، يقول قدامة ابن جعفر: "إن مناقضة الشاعر نفسه في قصيدتين أو كلمتين، بأن يصف شيئا وصفا حسنا، تم يذمه بعد ذلك ذما حسنا أيضا، غير منكر عليه ولا معيب من فعله، إذا أحسن المدح والذم، بل ذلك عندي دليل على قوة الشاعر في صناعته واقتداره عليها " (ابن جعفر، 1978، ص ص.19-20) فقيمة الشعر لا تنحصر في معناه، ولا في كون هذا المعنى مناقضا لمعان سبقته، بل تكمن في تشكيله الجمالي. 4. التفاوت في دائرة الإنتاج والتلقي

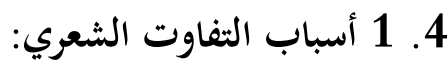


هناك أسباب تقف وراء ظاهرة التفاوت الشعري عند الشاعر، ويمكن تصنيف هذه

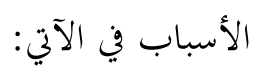

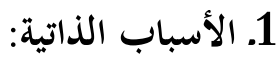

قد يرجع التفاوت الشعري عند الشاعر الواحد، إلى التحول المفاجئ في حياته الخاصة، فضلا عن التحول الذي يحدث بفعل التطور الطبيعي، الذي يشترك فيه مع غيره من عامة الناس، مثال ذلك التحول المفاجئ في حياة الشاعر الجاهلي امرئ القيس وفي شعره، فقد كان في بداية حياته منشغلا باللهو والصيد، ثم حدث له ما جعل حياته تتغيّر رأسا على عقب، وذلك هو مقتل أبيه، ويروي أبو الفرج الأصفهاني هذه اللحظات المفصلية في حياته فيقول: إن "حُجراكان طرد امرأ القيس، وآلى ألا يقيم معه أنفة من قوله الشعر، وكانت الملوك تأنف من ذلك، فكان يسير في أحياء العرب، ومعه أخلاط من شذاذ العرب من طييء وكلب وبكر بن وائل، فإذا صادف غديرا أو روضة أو موضع صيد، أقام فذبح لمن معه في كل يوم، وخرج إلى الصيد فتصيد ثم عاد فأكل وأكلوا معه، وشرب الخمر وسقاهم، وغنته قيانه. ولا يزال كذلك حتى ينفد ماء ذلك الغدير، ثم ينتقل عنه إلى غيره، فأتاه خبر أبيه ومقتله، وهو بدمُون من أرض اليمن، أتاه به رجل من بني عجل يقال له عامر الأعور أخو الوصّاف...[قال]: ضيعني صغيرا وحملني دمه كبيرا، لا صحو اليوم ولا سكر غدا، اليوم خمر وغدا أمر، فذهبت مثلا" (الأصفهاني، 1985، ج9،صك5)، وقد انعكس هذا التحول في حياة امرئ القيس على شعره فأصبح متفاوتا، وإذا كانت المعلقة تصور حياة الترف التي عاشها في المرحلة الأولى من حياته، فإن هناك عددا من القصائد التي وصلت إلينا من شعره، تكشف عن المرحلة الثانية منها. 
وقد لاحظ النقاد هذا التفاوت في شعر امرئ القيس، وألقوا باللائمة عليه، لأنه يأتي في شعره أحيانا بما يدل على "جلالة شأنه، وعظيم خطره، وبُعد همته" (المرزباني، د.ت، ص22)، فيقول مفتخرا بملكه، واصفا لما يماوله: فلو أن ما أسعى لأدنى معيشة كفاني ولم أطلب قليل من المال ولكنـما أسعى لمجد مؤثل وقد يدرك المجد المؤثل أمثالي ثم يأتي ويقول قول إعرابي متلفع في شملته، لا بتحاوز همته ما حوته خيمته: لنا غنم نسـوِقها غزار كأن قرون جِلَّتها العصيٌّ فتملأ بيتنا أقِطا وسمناً: وحسبك من غنى شبع ورِيُّ

إن هذه التهمة الموجهة لشاعرية امرئ القيس، لم تكن بسبب تفاوت شعره من الناحية الفنية، بل كانت بسبب تفاوته في المعنى، فهو في البيتين الأولينن يتحدث بلسان أمير وابن ملك، ويبدو عاليَ الهمة، ويمتلك الثقة الكافية في قدرته على بلوغ مراده، وفي البيتين التاليين، تتضاءل هذه الهمة، ولا يطلب من الحياة إلا ما يطلبه البسطاء من الناس. أما أنصار الشاعر فقد حاولوا أن يدافعوا عن شعره، لكن دفاعهم عنه لم يكن بنفي التهمة، من خلال البحث عن مبررات لهذا التفاوت في المعنى، ولم يكن بتوجيه القراء إلى القيم الجمالية في الأبيات الشعرية، بل بنفي هذا الشعر الذي لا يتناسب والهمة العالية في البيتين الأولين، لكن قصارى جهدهم لم يتجاوز قولهم: "إن كثيرا من شعر امرئ القيس لصعاليك كانوا معه، مثل عمرو بن قميئة وغيره" (المرزباني ، د.ت، ص313) وهناك من كان أكثر إنصافا وموضوعية، عندما وضع يده على السبب الأكثر وجاهة لهذا التفاوت

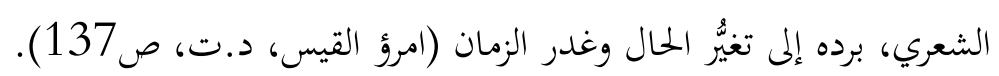




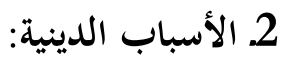

وقد يحدث التفاوت الشعري بسبب تحول الشاعر إلى عقيدة جديدة، وهذا ما

حدث مع الشاعرين المخضرمين، لبيد بن ربيعة، وحسان بن ثابت، شاعر رسول الله صلى الله عليه وسلم، أما الأول فتقول بعض الروايات إنه اعتزل قول الشعر، إذ " لم يقل لبيد في الإسلام إلا بيتا واحدا، وهو:

الحمد لله إذ لم يأتني أجلي حتى لبست من الإسلام سربالا"

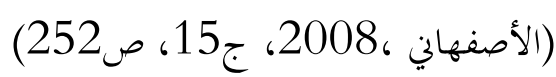

وفي رواية أخرى أن سيدنا عمر بن الخطاب رضي الله عنه، طلب من عامله على جلى صله

الكوفة، وهو المغيرة بن شعبة، أن استشد من قِبَلك من شعراء مصرك ما قالوا في الإسلام، فأرسل "إلى لبيد فقال: أنشدني، فقال: إن شئت ما عُفي عنه، يعني الجاهلية، فقال: لا، أنشدني ما قلت في الإسلام، فانطلق فكتب سورة البقرة في صحيفة، ثم أتى بها وقال: أبدلني الله هذه في الإسلام مكان الشعر" ( الأصفهاني ،2008، ج15،ص252)؛ غير أن الأخبار المروية عن هذا الشاعر، تؤكد أنه لم يتوقف عن قول الشعر تماما بعد الإسلام، لكنه لم ينشغل به كسابق عهده في الجاهلية، ومن يتأمل الشعر المنسوب إليه في المصادر بعد إسلامه، يدرك التحول الكبير الذي أحدثه إسلامه في حياته، كما يدرك شكل التفاوت في شعره، فلو قرأنا ـ على سبيل المثال ـ معلقتة الشهيرة، وقد قالها في الجاهلية:

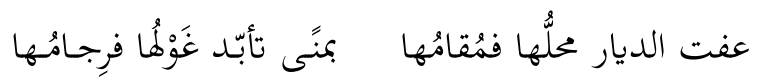

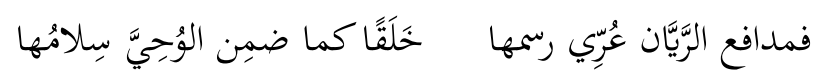
دِمنٌ تجرّم بعد عهد أنيسها حِجـج خلون حلالما وحرامها (العامري، د.ت، ص صن3 163) 
وقارناها بقوله في قصيدة بعد إسلامه، وتبلغ عدةما خمسة وثمانون بيتا: إن تقوى ربنا خيـر نفل وبإذن الله ريثي وعسل

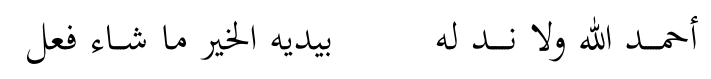

من هداه سبل الخير اهتدى اعم البال ومن شاء أضل

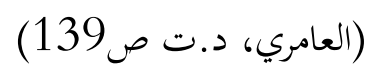

لاستطعنا أن نميز بين القوة والجزالة والإيقاع الصاخب في أبيات المعلقة، في مقابل التقريرية والمباشرة في قصيدته بعد إسلامه، مما يدل على وجود تفاوت فني بين شعره في المرحلتين، الأمر الذي دفع النقاد للتقليل من أهمية شعره في الإسلام، فقد سمع الأصمعي أستاذه أبا عمرو بن العلاء يصف شعره ويقول: "ما أحد أحب إلي شعرا من لبيد بن ربيعة، لذكره الله عز وجل، ولإسلامه، ولذكره الدين والخير، ولكن شعره رحى بزر" (المرزباني، ص84)، يريد "أنه ذو جعجعة وطنين، وليس وراءه كبير شيء" (عباس، 1993م،50)، وهذا الحكم النقدي فضلا عن كونه يفصل الشعر عن الدين، فإنه يكشف عن هبوط المستوى الفني لشعر لبيد بعد الإسلام.

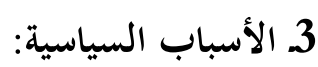

من الأسباب التي تقود إلى التفاوت الشعري عند الشاعر ارتباطه بالسياسة، وهذا ما حدث في الحقبة الأموية، حيث عمد خلفاء بني أمية لاستقطاب الشعراء، لترسيخ جانبين: "أحدهما: يتصل بتحويل الخحلافة إلى ملك وراثي، يرثه من يختارونه من أبنائهم، والآخر يتصل بتأكيد أحقيتهم في الولاية والحكم" (علي ، 1986،ص 375)، فكان أكثر الأحزاب تأييدا من الشعراء، ولا غرابة في ذلك، فقد كانت السلطة بيده، وكانت الأموال التي يغدقها على الشعراء وفيرة، وقد كرس هذا الوضع فكرة التكسب بالشعر، ودفع كثيرا 
من الشعراء المهمين، كجرير والفرزدق، إلى مدحهم والوقوف بصغهم ، كما انضم إليهم شعراء الشيعة، مثل أيمن بن خريم الأسدي. ويبدو أن العطاء هو الصلة التي كانت تربط هؤلاء الشعراء بالحزب الأموي الحاكم؛ فمذاهب بعضهم كانت شيعية، وملا آلت السلطة إلى حزب بني أمية ابتهوا إليه، فكتم بعضهم تشيّعله، ومضى في مدح بني أمية. وإلى جانب الإغراء المادي، تحول بعض الشعراء عن مذاهبهم بفعل التهديد

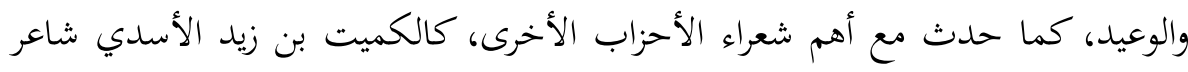
حزب الشيعة الأبرز، وعبيد الله بن قيس الرقيات، أهم شعراء حزب الزبيرين.

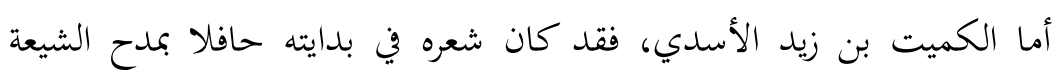

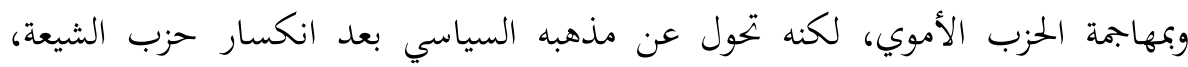

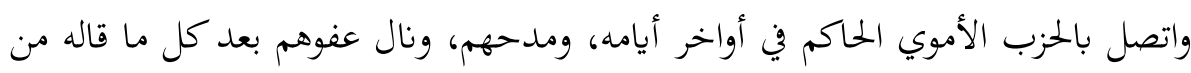

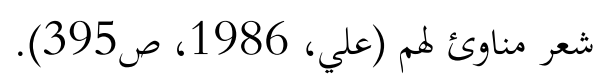
وأما عبيد الله فقد كان معروفا بإخلاصه للعقيدة الزبيرية، وتريضه على بني أمية، وهجائه اللاذع لمه، ونيله من حرماتم وأعراضهم، لكنه بعد انتهاء حزب الزبيريين ظل

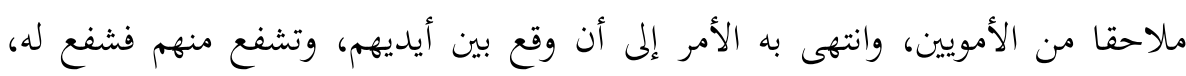

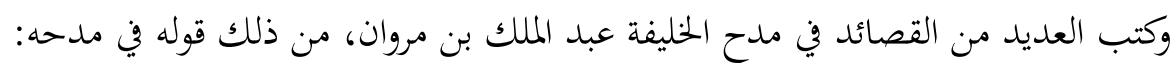

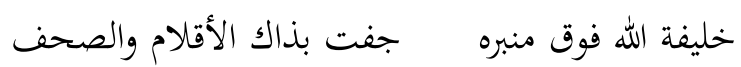
(ضيف، د.ت، ص299) 


\section{2 طبيعة الثفاوت الشعري}

يقود الحديث عن أسباب التفاوت الشعري إلى السؤال الآتي: ما المعايير التي

$$
\text { احتكم إليها النقد العربي القديم في التفاوت الشعري؟ }
$$

ويمكن تصنيف المعايير التي احتكم إليها النقاد في رصد هذه الظاهرة إلى ثلاثة

معايير: منها ما يتصل بالموضوع الشعري، ومنها ما يتصل بتصحيح الرواية، ومنها ما يتصل بالحالة النفسية للشاعر.

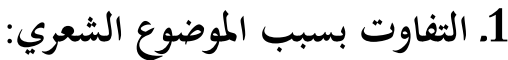

قد يرجع التفاوت الشعري إلى الموضوع الذي يكتب فيه الشاعر، فهناك

موضوعات محددة ـ وفق هذا التصور ـ تفسح المجال للإبداع الشعري، ويستحق بسببها أن يوصف الشعر بالقوة، وهناك موضوعات أخرى يضيق فيها المجال الإبداعي للشعر، ومن ثم يوصف الشعر الذي أُجزز فيها بالضعف، وقد عبر الأصمعي(210هـ) عن هذا النوع من التفاوت في نصه الشهير، وهو يتحدث عن شعر حسان بن ثابت فقال: "طريق الشعر إذا أدخلته في باب الخير لان؛ ألا ترى أن حسان بن ثابت كان علا في الجاهلية والإسلام، فلما دخل شعره في باب الخير ـ من مراثي النبي صلى الله عليه وسلم، وحمزة وجعفر رضوان الله عليهما، وغيرهم ـ لان شعره، وطريق الشعر هو طريق شعر الفحول، مثل امرئ القيس، وزهير، والنابغة، من صفات الديار والرحل، والهجاء والمديح، والتشبيب بالنساء، وصفة الحُمُر والخيل والحروب والافتخار، فإذا أدخلته في باب الخير لان" (المرزباني، ب ت،

وهذا النص النقدي دلالات مهمة، فهو أم النصوص التراثية التي يستدل بها على انحياز النقد العربي في وقت مبكر للنواحي الجمالية في النص الشعري، ويتجلى ذلك في 
فصله بشكل واضح بين الشعر والدين، بل إنه يتجاوز ذلك، حين يغالي في ربطه بين الحير وضعف الشعر.

ويتوقف أحد النقاد المعاصرين عند كلمتي: الخير واللين في هذا النص للكشف

عن معناهما، ويرى أن الأصمعي قد وضع مقابل كلمة اللين طريق الفحول، وهي تعني عند

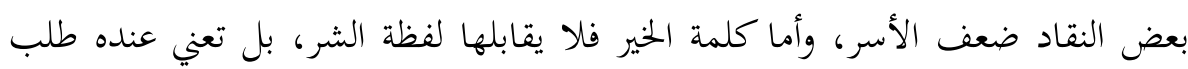

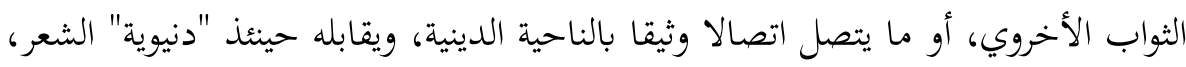
واتصاله بالصراع الإنساني في هذه الحياة، فالليونة والانحياز للخير مضادان للفحولة، (عباس، 1993، ص51) وبحسب هذا الفهم، فإن ما يصيب الشعر من ضعف أو قوة.

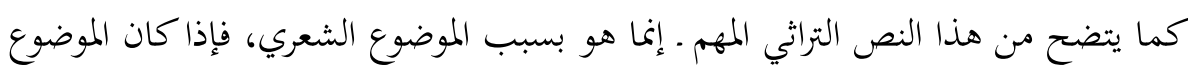

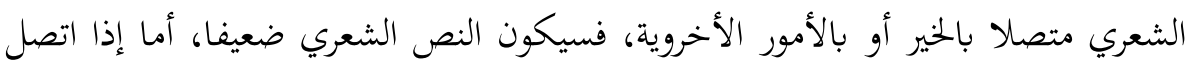

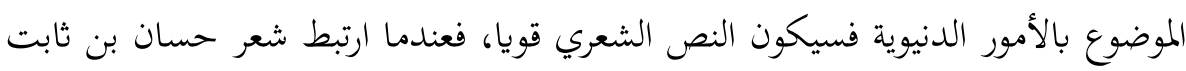
بالصراعات الدنيوية، كان شعره قويا، وعندما جاء الإسلام وارتبط شعره بالأمور الأخروية أصبح ضعيفا.

2 - 2 النفاوت بسبب تصحيح الرواية

وهو التفاوت الذي يرجع إلى اختلاف القائلين، فيما عرف بالانتحال، فما باليا يلاحظه الناقد من تفاوت في شعر الشاعر ليس مرده إلى الموضوع الشعري، كما هو الحال عند الأصمعي، الذي ربط قوة الشعر ب((طريق الفحول)) أي بالانغماس في الصراعات

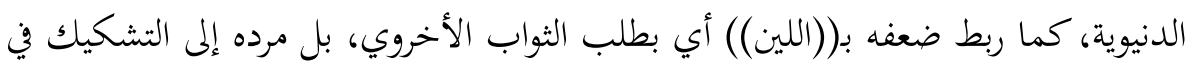

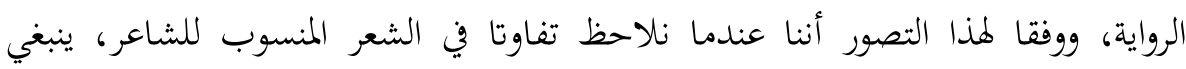

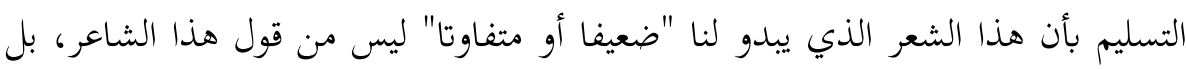


هو منسوب إليه، ومن ثم ينبغي أن نبحث له عن قائل آخر، كما حدث لأنصار الشاعر امرئ القيس، عندما برروا الأشعار الضعيفة المنسوبة إليه بقولمم : "إن كثيرا من شعر امرئ

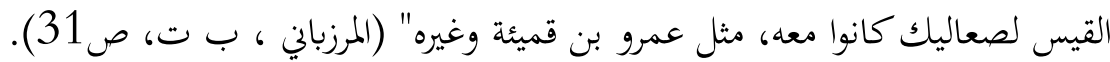

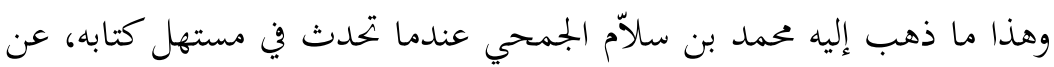
ظاهرة الوضع والانتحال، فقال: "وفي الشعر مصنوع مفتعل موضوع كثير لا خير فيه" (الجمحي، د.ت، ج1، ص4)، كما قدم تفسيره لأسباب ظهورها، والطريقة التي تمت بها،

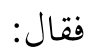

فلما راجعت العرب رواية الشعر، وذكر أيامها ومآثرها، استقل بعض العشائر شعر شعرائهم، وما ذهب من ذكر وقائعهم، وكان قوم قلت وقائعهم وأشعارهم، فأرادوا أن يلحقوا بمن له الوقائع والأشعار، فقالوا على ألسنة شعرائهم، ثم كانت

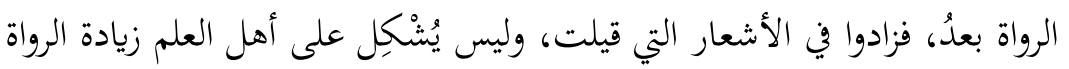

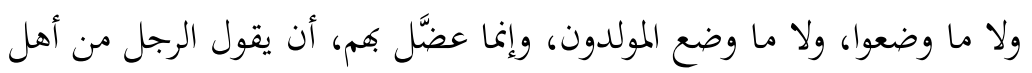

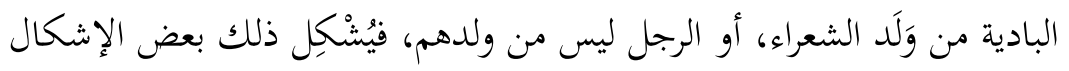

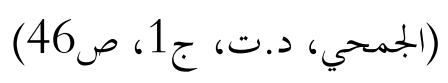

ولست هنا في سياق الحديث عن ظاهرة الانتحال، ولا عن مدى وجاهة هذا

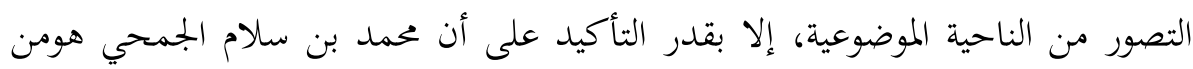

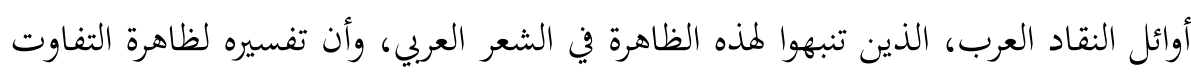
الشعري عند الشعراء مبنيُّ على هذه الفكرة. فقد فسر به سبب التفاوت الشعري عندما تحدث عن اللين الذي لاحظه في

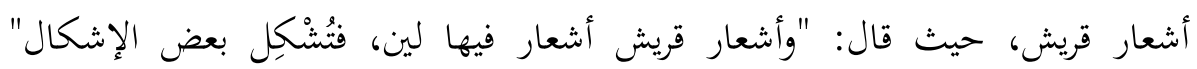


(الجمحي، د ـ ت،،ج1، ص245)، كما توقف عند قصيدة منسوبة إلى أبي طالب، يمدح فيها النبي صلى الله عليه وسلم:

وأبيض يُستسقي الغمام بوجهه ربيع اليتامى عصمة للأرامل

ورأى أنه "زِيد فيها وطولت، وسألني الأصمعي عنها، فقلت صحيحة جيدة،

قال: أتدري أين منتهاها؟ قلت: لا" (الجمحي، د.ت، ج1، ص244)، وتوقف عند حسان بن ثابت، وعده الشاعر الأول من طبقة شعراء المدن العربية، ووصفه بأنه "كثير الشعر جيده، وقد حمل عليه مالم يحمل على أحد، لما تعاضهت 1 قريش واستبَّتْ، وضعوا عليه أشعارا كثيرة لا تُنَقَّى"(الجمحي، د.ت، ج1،،ص215)، وقد مر بنا كيف أرجع النقاد سبب تفاوت شعر امرئ القيس إلى اختلال الرواية، عندما نسبوا بعض أشعاره المتهمة بالضعف، بأها لصعاليك كانوا معه. 3. - 3 التفاوت بسبب الثاعر

من الأسباب التي فسر بها النقاد ظاهرة التفاوت الشعري الحالة النفسية للشاعر، وقد تناول ابن قتيبة"276هـ" هذه الأسباب من ثلاثة جوانب: جانب يتصل بالحوافز النفسية الدافعة لقول الشعر، وجانب يتصل بالعلاقة بين الشاعر والزمن، وجانب يتصل بالعلاقة بين الشاعر والمكان (عباس، 1993، ص.111). 1. أما الحوافز النفسية الدافعة لقول الشعر عند ابن قتيبة، فهي خمسة: الطمع والشوق والشراب والطرب والغضب (ابن قتيبة، 1958، ج1، صو87). واللافت للنظر أن الغالب في شواهد ابن قتيبة على هذه الحوافز كان للطمع، وذلك يشير إلى شيوع ظاهرة التكسب في عصره، تلك الظاهرة التي ظهرت بوادرها في 1 ـ تعاضهوا: تناهشوا ورمى بعضهم بعضا بالعضهية، وهي الإفك والبهتان والشتيمة. 
الشعر الجاهلي، وعند الشاعر الأعشى ميمون بن قيس، ثم تنامت في العصور اللاحقة، ومن ذلك أن الكميت بن زيد الأسدي، كان يتشيع لبني أمية، وينحرف عنهم في الرأي والهوى، لكن مدائحه فيهم كانت أجود من مدائحه في آل أبي طالب (ابن قتيبة، 1958،

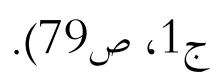
2 العلاقة بين الثاعر والزمن: من الأسباب التي تقود إلى التفاوت الشعري عند الشاعر توقيت إبداعه للقصيدة، فإذا اختار توقيتا مناسبا استطاع أن يبدع شعرا جيدا، وإذا لم يوفق في اختيار الوقت المناسب استعصى عليه قول الشعر، يقول ابن قتيبة: "وللشعر أوقات يُسرع فيها أتئهة، ويُسمح فيها أبيُه" (ابن قتيبة، 1958، ص80)، وبالمقابل فإن له "تارات يبعد فيها قريبه، ويستصعب فيها رِِّضه" (ابن قتيبة، 1958، ص. 80)، وقد حدد هذه الأزمنة في وقتين، أول الليل قبل تغشّي الكرى، أي قبل وقت النوم، وصدر النهار قبل

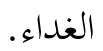

3. التفاوت الثعري والمكان: يرى ابن قتيبة أن المكان يؤثر في الإبداع الشعري، ومن ذلك الخنلوة في السجن، والخلوة في المسير (ابن قتيبة، 1958، ص. 80)، وفي حال عدم توفر الحالة المناسبة للشاعر، أو الوقت والمكان الملائمين لقول الشعر، سيكون ما ينظمه الشاعر مختلفا ومتفاوتا. والمتأمل في فهم نقاد القرن الثالث الهجري لطبيعة التفاوت الشعري عند الشاعر الواحد، يمكنه القول إنه كان يصدر عن وعي نقدي لطبيعة التطور الشعري، لكن هذا الوعي كان محكوما بالحركة النقدية في عصره، إذ لم يكن بوسعه أن يتخلص من تأثير الثقافة الشفاهية في ترجمة هذا الوعي، ولئن سمحت هذه الثقافة بشيء من التذوق والتأثر، فإنها لم 
تُكّكن الناقد من الفحص والتأمل والنظر، مما هو من مقتضيات الثقافة الكتابية، ولذلك جاء الحديث عن التفاوت الشعري عند الشاعر الواحد حديثا عاما. فالناقد إما أن يتجه وجهة الموضوع الشعري (الأصمعي)، وهي خطوة طيبة، كان من الممكن أن تفضي إلى العناية بالنص الشعري، وبيان وجوه التفاوت فيه، لكنها أسلمته إلى عبارات عامة، تمس التفاوت الشعري، كحديثه عن لين الشعر وضعفه، بسبب ارتباطه بموضوعات الخير، أو فحولته وقوته، عندما يرتبط بالنشاط الإنساني، وما إلى ذلك من المصطلحات العامة، التي كانت بحاجة لمن يتوقف عندها ويطورها. وصحيح أن هناك من حاول (الجمحي) تطوير مفهوم الفحولة، أي قوة الشعر وضعفه، أو فحولته ولينه، فإذا كان الشاعر عند الأصمعي فحلا أو غير فحل، فإن الفحولة عند الجمحي تتفاوت، وهي درجات، وبالرغم من ذلك فإن الجمحي لم ينظر إلى الفحولة من موقف تطوري، بل نظر إليها من موقف ثابت (عباس، 1993،صو15و81)، أما مقياس اللين فإنه لم يقرنه بالخير كما فعل الأصمعي، بل قاده إلى الشك في تقبل الشعر، ومن ثم البحث عن الأصيل منه والزائف، بسبب انشغاله مع علماء عصره بإرهاصات التحول إلى الثقافة الكتابية، وملازماتا، من نقد الرواية، والبحث عن صحتها. وإما أن يوجه الناقد "ابن قتيبة" وعيه بهذه الظاهرة إلى مصدر الإبداع الشعري، أو الش منشئ الأدب، فيتحدث عن دوافع الشعر، وعن الزمان والمكان المناسبين لإبداعه، وهي أفكار جديرة بالتأمل، لأها تراعي الحالة النفسية للشاعر، وما يعتريها من تقلبات.

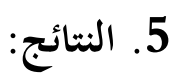
1. لم يرد مصطلح التفاوت الشعري في معاجم النقد الأدبي القديم ولا في معاجم البلاغة العربية، ولكنه كان حاضرا بمعناه ودلالته في الممارسات النقدية. 
2. يتقاطع مصطلح التفاوت الشعري في بعض دلالاته مع مصطلح التناقض الشعري، وهو مصطلح كان حاضرا عند الشعراء والنقاد على السواء.

3. يكشف اهتمام النقاد بظاهرة التفاوت الشعري عن وعي نقدي بأهمية ظاهرة التفاوت الشعري وتأثيرها في حركة التطور الشعري.

4. كان لتأثير الثقافة الشفاهية دور بارز في تعامل نقاد القرن الثالث الهجري مع هذه الظاهرة الشعرية، فبالرغم من وعي النقاد جما، وتقديم تصوراتم لمعلجتها، فإِمم لم يستطيعوا تأمل هذه الظاهرة تأملا يفضي إلى رأي نقدي موضوعي لها. 5. اختلفت آراء النقاد حول هذه الظاهرة، فبعضهم حاول معالجتها من الخارج، عندما عزا وجودها إلى صنع الرواة، وحاول البعض الآخر إرجاعها إلى الداخل، عندما ردها إلى

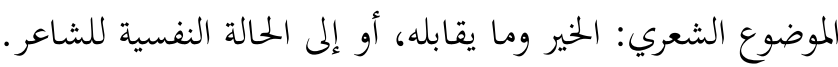
6. كان رأي ابن قتيبة في هذه القضية أقرب الآراء إلى الموضوعية، عندما رد وجود هذه الهري

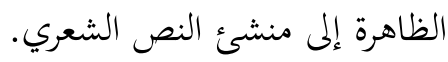

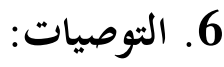

1. التأكيد على أهمية التراث النقدي، وأن العودة إليه بمناهج علمية قد يساعد في حل بعض المعضلات النقدية المعاصرة.

2. دعوة الباحثين إلى مقاربة موضوع التفاوت الشعري في التراث النقدي من زاوية الشفاهية والكتابية.

3. ضرورة متابعة هذه الظاهرة النقدية في القرون التالية، لما تتوفر عليه من مذاهب نقدية متعددة الاتحاهات، ومختلفة المشارب. 


\section{المصادر والمراجع:}

إبراهيم، طه أحمد (1985). تاريخ النقد الأدبي عند العرب من العصر الجاهلي إلى القرن الرابع الهجري. بيروت: دار الكتب العلمية.

إسماعيل، عزالدين (2007). الأدب وفنونه. ط9. القاهرة: دار الفكر العربي.

الأصفهاني، أبو الفرج (2008). الأغاني. ط3. (تحقيق: إحسان عباس). بيروت: دار

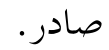

الأنباري، أبوبكر محمد (ب ت). شرح القصائد السبع الطوال الجاهليات، ط 6. (تحقيق:

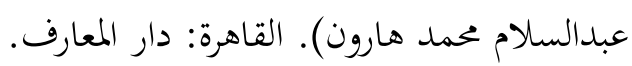

الجاحظ، أبو عثمان عمرو بن بحر (1996). الحيوان. (تحقيق: عبد السلام هارون). بيروت: دار الجيل.

ابن جعفر، قدامة (1978). نقد الشعر. ط3. (تحقيق: كمال مصطفى). القاهرة: مكتبة الخانجي.

الجمحي، محمد بن سلاّم (ب ت). طبقات فحول الشعراء. (تحقيق: محمود محمد شاكر). جدة: دار المدني.

الرازي، فخر الدين (2000م)، الثفسير الكبير أو مغاتيح الغيب، ط3. بيروت: دار الكتب العلمية.

ضيف، شوقي (ب ت). تاريخ الأدب العبي العصر الإسلامي. ط16. القاهرة: دار المعارف

ابن عاشور، محمد الطاهر (ب ت). تنسير التحرير والثنوير. تونس: الدار التونسية للنشر. العامري، لبيد بن ربيعة (ب ت). ديوان لبيد. بيروت: دار صادر . 
عباس، إحسان (1993). تاريخ النقد الأدبي عند العرب: نقد الشعر من القرن الثاني حتى القرن الثامن الهجر. عمان: دار الشروق.

علي، محمد عثمان (1986). في أدب الإسلام: عصر النبوة والراشدين وبني أمية. ط2. بيروت: دار الأوزاعي.

ابن قتيبة، عبدالله بن مسلم (1958). الشعر والشعراء. ط2. (تحيق: أحمد محمد شاكر) القاهرة: دار المعارف

مجمع اللغة العربية (2005). المعجم الوسيط. ط3. القاهرة: الهيئة المصرية العامة للكتاب. امرؤ القيس (ب ت). ديوان امرئ القيس. ط5. (تحقيق: محمد أبو الفضل إبراهيم).

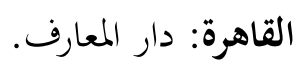

المرزباني، محمد بن عمران (ب ت). الموشح: مآخذ العلماء على الشعراء في عدة أنواع من

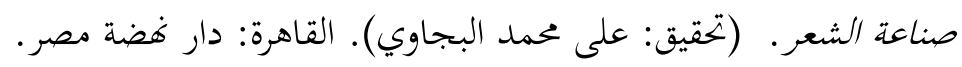
ابن منظور (1990)، لسان العرب. بيروت: دار صادر.

الناقوري، إدريس (1984). المصطلح لنقدي في نقد الشعر: دراسة لغوية تاريخية نقدية. ط2. طرابلس: المنشأة العامة للنشر والتوزيع والإعلان. 